\title{
The Occurrence of Clithon retropictus (von Martens in Kobelt, 1879, Gastropoda: Neritidae) in Jeju Island, Republic of Korea
}

\author{
Ronald. G. Noseworthy ${ }^{1}$, Mostafizur Rahman Mondol ${ }^{2}$, Se-Jong $\mathrm{Ju}^{3}$ and Choi, Kwang-Sik ${ }^{2}$ \\ ${ }^{1}$ Field Associate, Shellfish Aquaculture and Research Laboratory, School of Marine Biomedical Science, Jeju National \\ University, 66 Jejudaehankno, Jeju, 690-756, Republic of Korea \\ ${ }^{2}$ School of of Marine Biomedical Science, Jeju National University, 66 Jejudaehankno, Jeju, 690-756, Republic of Korea \\ ${ }^{3}$ Deep-Sea and Marine Resources Research Department, Korea Ocean Research \& Development (KORDI), Ansan 425-600, \\ Korea
}

\begin{abstract}
The neritid species Clithon retropictus inhabits rivers and estuaries along the southern coast of the Korean mainland but has not been previously reported from Jeju Island. In 2007 and 2011 specimens of this species were obtained from two separate localities on the south coast of the island. Comparisons were made with von Martens' original description, specimens from the Korean mainland, and illustrations and descriptions in the literature. Although there were some differences in color and markings, and slight differences in morphology, the specimens from Jeju Island compare well with those from the mainland and in the literature. The shells of this species become more ovate and more eroded with age. In one locality, a small river, specimens of the pleurocerid Semisulcospira libertina (Gould, 1859), were found adjacent to, and coexisting with, a population of $C$. retropictus, an association that often occurs. The occurrence of Clithon retropictus represents a range extension to Jeju Island.
\end{abstract}

Key words: Clithon retropictus, Neritidae, Estuary, Jeju Island, species report, malacology

\section{INTRODUCTION}

Jeju Island, Korea's largest and southernmost island, is a volcanic island located about $80 \mathrm{~km}$ south of the mainland. The freshwater mollusk fauna is depauperate, only 8 species in 4 families, because the rivers are dry for most of the year due to the porous nature of the volcanic rock which comprises most of the island. There is also a relative absence of standing water in the form of lakes and ponds. Only one operculate mollusk, Semisulcospira libertina, belonging to the Pleuroceridae, has been previously recorded (Noseworthy et al., 2007).

The Neritidae is a family of prosobranch mollusks distributed all over the world, in mainly tropical and

Received: April 2, 2012 ; Accepted: May 8, 2012 Corresponding author: Choi, Kwang-Sik

Tel: +82 (64) 754-3422 e-mail: skchoi@jejunu.ac.kr $1225-3480 / 24429$ subtropical regions, but is sometimes also found in temperate areas. They occur mainly in marine environments but are also found in freshwater, brackish water (Clithon and Neritina), and even terrestrial habitats (Neritodryas, Pace, 1996).

Many authors have treated Clithon as a subspecies of either Neritina or Theodoxus; however, because of differences in the reproductive system and morphology of the operculum, Clithon is now regarded as a distinct genus (Pace, 1996). The genus Clithon (subfamily Theodoxinae Montfort, 1810) is distributed in tropical regions of Asia, and the Pacific and Indian Ocean islands (Haynes, 2005). The shells are subglobose and may be sculptured with ridges, wrinkles, or spines. The edge of the columella has a relatively large tooth with smaller teeth in the central area. The operculum is calcareous, as in the rest of this family, and is smooth with a narrow horn border and curved indentation, where the larger tooth of the columella fits (Tan and Clements, 2008). Two subgenera are usually recognized, Clithon and 
The Occurrence of Clithon retropictus (von Martens in Kobelt, 1879, Gastropoda: Neritidae) in Jeju Island,

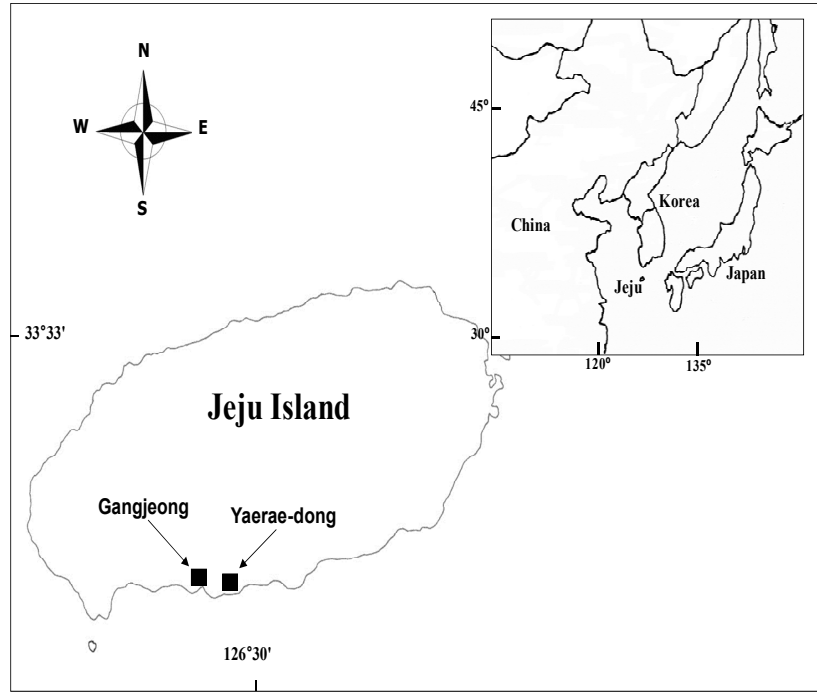

Fig. 1. Jeju Island, showing the survey localities of $C$. retropictus.

Pictoneritina, which is used mainly for several fossil species (Eichhorst, pers. comm.)

\section{MATERIALS AND METHODS}

In 2007, a specimen of Neritidae was collected from shell drift at Yaerae-dong, near the mouth of a small river, adjacent to a sanitation plant, approximately 8 $\mathrm{km}$ west of Seogwipo, on the southern coast of Jeju Island (Fig. 1). This specimen appeared unlike the other two fairly common neritids, Nerita (Heminerita) japonica Dunker, 1860 and N. (Theliostyla) albicilla Linnaeus, 1758, found on the island, and subsequent comparison with specimens figured in the literature affirmed that the specimen in question appeared to be C. retropictus. Also, in 2007, another collection of neritid specimens was obtained from a small, shallow brackish-water estuary southwest of the town of Gangjeong, and approximately $6.5 \mathrm{~km}$ east southeast of the previous location (Fig. 1). The specimens were also identified as C. retropictus.

On June 13, 2011, another field survey was conducted. This time the lower reaches of the river adjacent to the September, 2007 locality were examined in order to ascertain if live specimens could be found. Four specimens were obtained, one exposed on a rock with a thin film of silt near a small rock dam just above the bridge across the river, and the

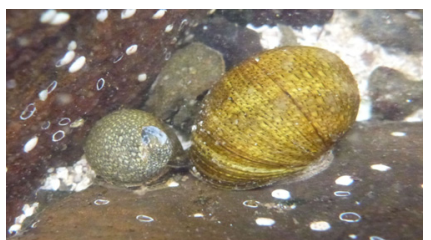

a

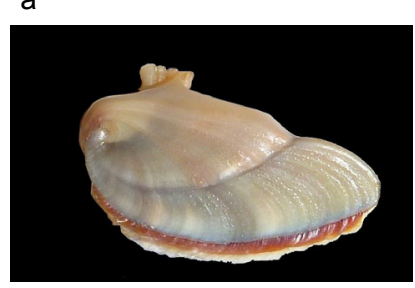

C

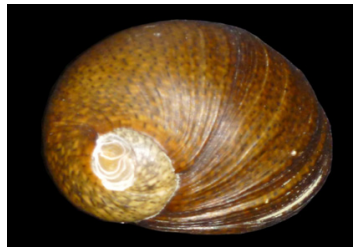

$\mathrm{b}$

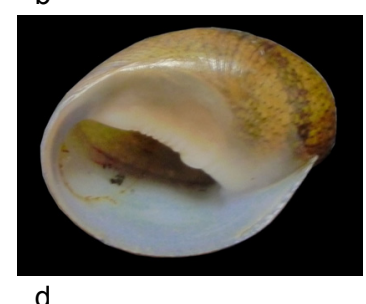

d
Fig. 2. C. retropictus, Gangjeong estuary. (A - living specimens (Photo provided by Koh Dong-Bum), B dorsal view, $\mathrm{C}$ - operculum (outer surface), D - ventral view)

other three on the sides of rocks also in the vicinity of the dam. In this area the current was moderately strong. This locality's close proximity to the ocean suggested that, at the highest tides, or during periods of strong wave action, the water in this area might be mixed with seawater, creating somewhat brackish conditions.

No specimens were found above the rocky area of the dam; however, a subadult specimen of the pleurocerid Semisulcospira libertina (Gould, 1859), an ovoviparus snail distributed in freshwater streams and lakes in Korea and Japan (Ohara and Tomiyama, 2000), was obtained from a silt-covered rock, near shore about $50 \mathrm{~m}$ above dam in slowly flowing water, and four others, all subadults, were found exposed and on the undersides of rocks along a $100 \mathrm{~m}$ stretch on both sides of river as far as the first bend in the river, the end of the sampling area, a distance of about $600 \mathrm{~m}$ upstream from the bridge.

In July, 2011 the Gangjeong locality was visited again to obtain live specimens and examine the habitat of this species. A small, slowly-flowing, muddy stream opens into the estuary. Thirteen specimens, one dead, were obtained from silt covered rocks in shallow water near the shoreline, and photos were taken of several specimens in situ (Fig. 2a). Dead shells of 14 marine species were also obtained, as well as a live specimens of Nerita (Heminerita) japonica, 
confirming the brackish nature of the water in this area.

In November, 2011 a second visit to the river locality was made. The rock dam had been removed, and this had changed the character of the river. No $C$. retropictus were obtained, either at the site where they had previously occurred or below the bridge across the river.

The current in this river varies between areas of moderately strong flow and quieter, gently-flowing areas. A careful search was made above the bridge from the former dam site to the bend in the river, a distance of about $600 \mathrm{~m}$, the same area that was sampled the previous June. Six specimens of $C$. retropictus were obtained from both swiftly flowing water and quieter areas, occurring further upstream than during the previous survey. Fourteen specimens of Semisulcospira libertina were obtained, mainly from areas of slower flowing water. C. retropictus was found mainly on larger rocks but a few were on smaller ones; S. libertina occurred on both gravel and larger rocks. All rocks were covered with a film of algae, which was heavier in quieter areas. A total of 10 specimens of $C$. retropictus were obtained from both surveys of the river.

A second survey of the estuary was made in November, 2011 in order to establish more precisely the location and size of this population. It preferred rocky substrates in shallow, quiet areas, and tended to avoid sand which was widespread in this area and may inhibit the spread of the population. Larger individuals inhabited the undersides of rocks, while medium-sized and smaller individuals were found exposed on rocks or in crevices. The muddy substrate in the stream has most likely inhibited the spread of this population into fresh water.

Specimens obtained from both localities were photographed and measured, and detailed descriptions were made for comparision with specimens from mainland Korea, and also with figured specimens in the literature and on the Internet. Also relevant publications, in particular dealing with the morphology and ecology of this species, were examined. Voucher specimens are kept at the
Shellfish Aquaculture and Research Laboratory, Jeju National University.

\section{RESULTS}

The 10 specimens from the river near the sanitation plant range in length from 1.1 to $2.2 \mathrm{~cm}$, and in width from 0.9 to $1.8 \mathrm{~cm}$; the smallest specimens were obtained during the second visit to the river. Nine are younger specimens with one adult. The 13 specimens from the estuary range in length from 1.5 to $2.4 \mathrm{~cm}$, and in width from 1.2 to $1.9 \mathrm{~cm}$, with seven specimens measuring over $2 \mathrm{~mm}$ in length. This is a larger lot with more morphological and some color variation. A comparison of the specimens in both lots show mainly similarities but there are several differences. The spire is more eroded in estuary specimens, some older specimens with pitting near the aperture. All specimens from the estuary exhibit strong corrugations, probably caused by environmental factors (Shigemiya and Kato, 2001), but they are found on only one, the largest, from the river, all others exhibiting weaker ridges. The color of most specimens from both localities is shades of olive, although some estuary specimens are brownish-grey. (It should be noted that the overall color of the shell is a function of the periostracum: its thickness determines the darker or lighter shadings.) Furthermore, the shape of the spots is more variable in estuary specimens, and the denticulations on the inner lip may sometimes be slightly more defined. The outer lip is thinner in the smaller specimens from both localities, allowing the spots on the outer surface to be seen through the shell, but thicker and opaque in the larger specimens. Also, the smallest specimens, especially those from the river, exhibited weak shouldering, possibly a feature of immature individuals.

Not mentioned in the literature consulted is the presence of a whitish rim on the parietal shelf, adjacent to the aperture and varying in width; also, the operculum exhibits two interesting features: the presence of a thin bluish-grey line, of varying degrees of development, on the inner side adjacent to the red lamella along the outer margin, and the end of the 
The Occurrence of Clithon retropictus (von Martens in Kobelt, 1879, Gastropoda: Neritidae) in Jeju Island, Republic of Korea

peg is usually somewhat smooth but may sometime exhibit small points.

Seven specimens were obtained in the second survey of the estuary, and they closely resembled those acquired in June. However, there was a wider range of size and age. About $70 \%$ of the shell surface of the oldest and largest specimen was heavily eroded, and several other specimens exhibited varying amounts of erosion on the body whorl as well as the spire. It appears that the amount of erosion is generally related to the age of the individuals. Also, although most shells, as in the previous survey, were shades of olive, two specimens were dark brown with yellow spots. The size of the smallest and largest individuals sampled ranged from L. $1.1 \mathrm{~cm}$; W. $0.9 \mathrm{~cm}$ to L. $2.8 \mathrm{~cm}$; W. $2.3 \mathrm{~cm}$, and the estimated ages of those specimens was one to eight years. Because they were obtained after most of this study was completed, they have not been included in the statistical analysis.

The specimens from the two localities compare well with the original description (Von Martens, 1879). The shape is similar, with the presence of corrugations, "closely striate", and a dull sheen, "not very shiny". The aperture is "moderately sloping" in adult specimens. Apart from the presence of somewhat rectangular spots on some of the Jeju specimens, the main difference is in color; the aperture may exhibit olive or purplish shadings, and the parietal shelf is usually darker with shades of olive. With reference to the illustrations in the original description, the columella exhibits what appears to be an excavation in the lower half of the parietal shelf. In fact, several of the younger specimens from both localities possess a slight excavation in this area although the parietal shelf in the more mature specimens is smoother.

In order to ascertain any possible differences in morphology between Jeju Island specimens and those from mainland Korea, as well as published information, a series of comparisons was carried out.

Specimens from both localities were compared with several from the mouth of the Tamjin River, Jeollanam-do (South Jeolla Province), in the southwest of the Korean mainland, provided by Koh,
Dong-bum. These appear to be dead specimens. Their spires are eroded, and they are smoother than island specimens, which possess stronger corrugations. The aperture color is the same for mainland and river specimens, grayish, but the estuary specimens show a wider variety of shading. The parietal shelf is lighter than in island specimens and the denticulations slightly stronger. The color is brownish and somewhat lighter, but darker in island specimens, possibly because of the presence of the periostracum; however, both mainland and estuary specimens exhibit some banding. No opercula or periostraca were available with the mainland specimens for comparison.

The Jeju specimens were also compared with a detailed description provided by Tom Eichhorst, a specialist in the Neritidae. The shells correspond well with the description, with the eroded spires exhibiting the "false spire" mentioned by Eichhorst (pers. comm.; see above). On the other hand, there are several differences: the parietal shelf color is somewhat darker than the light bluish grey mentioned in the description; the periostracum is sometimes thinner; the spots, instead of yellow, are mainly of lighter olive shades; and the opercula exhibit varying degrees of development of the central groove and the red lamella along the labral margin, also mentioned in the description. Eichhorst, referring to the specimens he examined, gives a size range of 8-17 $\mathrm{mm}$ which is smaller than that recorded from both localities.

Comparisons were also made with the published literature. Two Korean faunal studies, Kwon et al. (2001) and Min et al. (2004), included the same description and illustration of $C$. retropictus. As stated above, the single specimen illustrated was collected in Jeollanam-do (South Jeolla Province). The specimen figured appears to be a dead one, with a prominent eroded spire. Dimensions of $1.4 \mathrm{~cm}$ and $1.4 \mathrm{~cm}$, length and width respectively, are also given, which is quite smaller than full-grown Jeju specimens. Also, the shape of the island specimens is more oblong, but smaller specimens are rounder. Overall, the island specimens appear quite similar to the description provided. It states that the species has four whorls, 
which appears to be the case in the larger island specimens, with the large body whorl and three quite smaller ones visible on the spire of specimens with little erosion. There is some difference in color, with the description stating a brown color, as is the case with the Jeollanam-do specimen mentioned above, but the Jeju specimens exhibit mainly shades of olive, usually dark, although a few may have brownish shading. The description also mentions "yellow and black triangular spots"; the spots on the island specimens have mainly lighter olive shades, but some may have shades of yellow. Although the spots are mainly triangular, they are usually uneven and varied in shape and size. Another description and illustration is found in Kwon et al. (1993). They figure what appears to be a fresh specimen, although no operculum is included. This figure shows a greenish-brown shell with two lighter bands; some island specimens also exhibit such banding. The dimensions given are the same as those in the above publications, and the description is similar to the previous one. The habit given: "freshwater near the seacoast", agrees well especially with the specimens found in the river above the bridge only a few meters from the seacoast

With reference to the Japanese literature, Okutani (2000) gives good illustrations of this species (as $C$. retropicta), one apparently live-taken and also what appears to be a dead specimen without periostracum. The shell length is given as $1-3 \mathrm{~cm}$, and the length of our specimens falls within this range. The former specimen agrees well with many of the island specimens, being dark olive with spots most visible on the ventral area near the aperture. The other specimen is brown with only black speckles visible. The short description is quite similar to the Jeju specimens. Hirase (1951), Kira (1964), and Habe (1975b) figure specimens, all which are shades of brown, which are quite similar to ours. In the Hirase figure the central groove in the operculum is clearly visible, as in some of our estuary specimens. Habe gives no dimensions for his specimen but, for Hirase and Kira's specimens, the dimensions are L: $1.8 \mathrm{~cm}$; W: $1.4 \mathrm{~cm}$ (Hirase) and L.: 2.6; W: $2.0 \mathrm{~cm}$ (Kira). The small dimensions for Hirase's figure suggests a young specimen while the specimen figured by Kira is somewhat smaller than the largest specimen collected in our study. Habe (1975a) gives dimensions of L: 2.5 $\mathrm{cm}$ and W: $2.0 \mathrm{~cm}$, which are similar to those of our larger specimens, and figures a specimen which is similar to ours, having variable-shaped spots and a thin outer lip which allows the spots to show through. As stated before, this is also characteristic of our younger individuals.

\section{DISCUSSION}

C. retropictus was described by von Martens as "Neritina retropicta", and the type locality was given as "Japan". He gave a condensed description followed by a more detailed analysis. His original description, translated from Latin, is as follows: "Shell oblong-semiglobose, closely striate, not very shiny, dark olive-green, spotted with numerous yellow spots, wedge-like in front, black margin toward the rear; spire prominent, usually eroded, suture appressed, with some cracks, moderately decreasing in front; aperture moderately sloping, wide, grey-blue within; outer lip semicircular, columella moderately sinuate and bluntly toothed; columellar area pale yellowish-gray, finely wrinkled, leathery, terminated indistinctly toward the rear." (von Martens, 1879). He also provided three illustrations (Pl. 17, figs. 18, 19, 20). The first is a detail of the triangular color pattern (Fig. 3a), and the second and third show the shell, both dorsal and ventral aspects (Fig. 3b)

The shell is lightweight with a thin lip. The spire is usually eroded but the final whorl extends beyond it, creating a "false spire" (Eichhorst, pers. comm.). The shell is covered with a brown periostracum and numerous growth striae, and the columella exhibits weak teeth (Fig. 2b \& d). The tan-colored operculum has a dark red corneous strip along the outer edge, not mentioned by von Martens, with a small peg (apophysis) on the upper portion (Fig. 2c). The periostracum is translucent, and shells without the periostracum have a light grey color with white tents (Eichhorst, pers. comm.).

C. retropictus is a typical euryhaline gastropod 
The Occurrence of Clithon retropictus (von Martens in Kobelt, 1879, Gastropoda: Neritidae) in Jeju Island, Republic of Korea

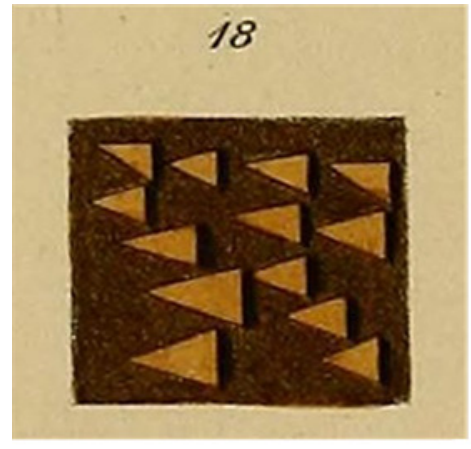

$A$

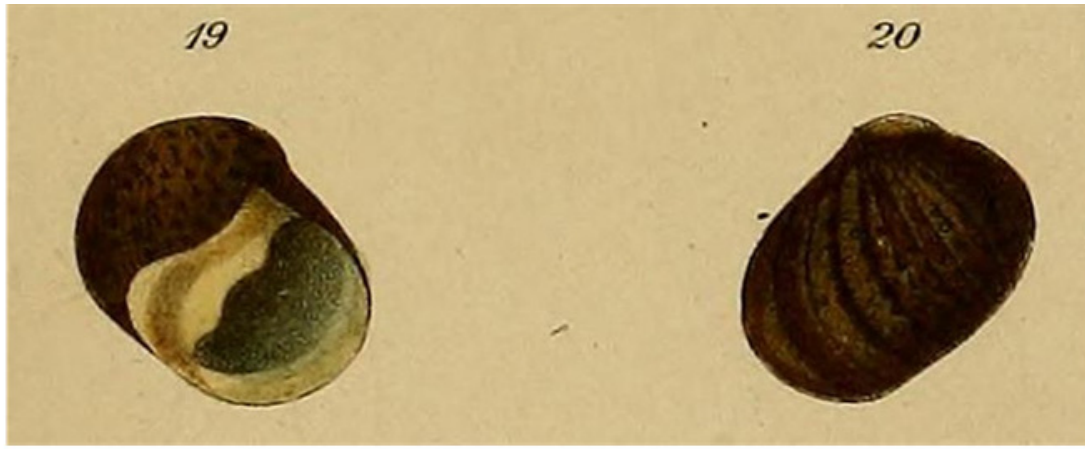

$B$

Fig. 3. "Neritina retropicta" showing color pattern (A), and dorsal and ventral views (B) (from von Martens, 1879).

(Matsuoka et al., 1999), and can survive a wide range of salinity. The species is a host of Vibrio parahaemolyticus, a bacterium which, when ingested, causes gastrointestinal illness in humans (Kumazawa et al., 1988). C. retropictus is distributed from Japan and Korea to Taiwan (Eichhorst, pers. comm.). In Korea it has been reported from both southern coastal provinces, Jeollanam-do (South Jeolla Province) and Gyeongsangnam-do (South Gyeongsang Province, Kwon et al., 1993; Kwon et al., 2001; Environmental Bucket, 2001; Min et al., 2004). However, it has not been previously reported from Jeju Island. Although nine species of Clithon are reported from Japan (Neritopsine Gastropods, 2010), only $C$. retropictus has been previously reported from Korea.

The specimens obtained from both locations were quite homogeneous in morphology and color, and differences were slight. Haynes (2005) states that the shells of many Clithon specimens in a particular stream can resemble one another in color and markings. This was certainly the case in the present study. Also, while the shells from the river and estuary differed from each other in several aspects, those differences were not profound; the main differences being size and the degree of erosion, the estuary specimens being somewhat larger and showing much more erosion.

The river specimens from the first survey were all obtained in the same location, on rocks directly above a small dam immediately upstream from a bridge. Below the dam, on the seaward side of the bridge, was a small brackish water area. Furthermore, the presence of dead specimens of marine shells near the dam suggested, as stated above, that the river water at this point may have sometimes become mixed with salt water. The second survey revealed that, with the removal of the dam, brackish conditions now existed in that area and no Clithon specimens occurred there, but were found immediately above this area. Therefore, the area where the specimens were obtained, in both surveys, may be regarded as the upstream limit of brackish water. According to Kobayashi and Iwasaki (2002), this area is significant with regard to the distribution of $C$. retropictus in several ways: it is in this area that the abundance of specimens is the greatest, the mean shell width is the smallest, and the sex ratio, between females and males is always nearly $1: 1$, while elsewhere females outnumber males approximately 4 to 1 (Shigemaya and Kato, 2001).

The average size of the ten specimens from the river was $1.5 \mathrm{~cm}$ x $1.3 \mathrm{~cm}$, length and width respectively. This is significantly smaller that the average size of the estuary specimens which was 2.0 $\mathrm{cm} \times 1.6 \mathrm{~cm}$, length and width respectively. Nine of the ten river specimens were rather small with little spire erosion, and thin, somewhat translucent, outer lips indicating subadult specimens. Most of the specimens obtained in both surveys were found just above the brackish water area. It may be that, in the area sampled, possibly the upstream limit of brackish water, the mean shell width would be the smallest for this population. 


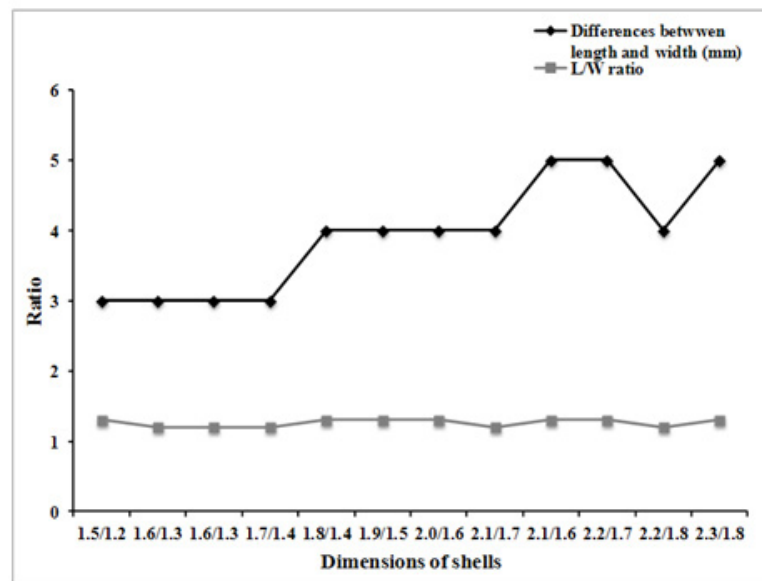

A

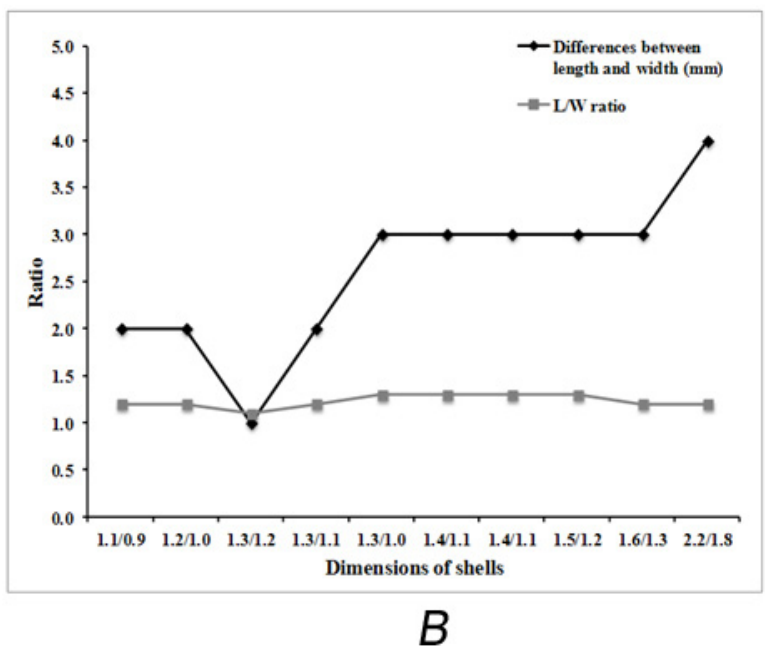

Fig. 4. Differences between $L$ and $W(\mathrm{~mm}$ and ratios) in estuary $(A)$ and river (B) specimens).

In the first survey five subadult specimens of Semisulcospira libertina were obtained upstream from the Clithon locality; however, 14 specimens, from juvenile to adult, were found in the second survey. This pleurocerid is found only in freshwater while the neritid occurs in both fresh and brackish water. According to Ohara and Tomiyama (2000) and Furujo and Tomiyama (2000), S. libertina and C. retropictus may coexist in the same place, an example of niche segregation. At the type locality for $S$. libertina (Shimoda, Honshu, Japan), C. retropictus was the dominant species (Davis, 1969). The two species have different food preferences: $C$. retropictus is herbivorous while $S$. libertina is polyphagous. There is also a difference in microhabitats: S. libertina tends to prefer quiet water to stronger current, and $C$. retropictus has the opposite tendency (Ohara and Tomiyama, 2000). The locations of each species were separate from each other in the first survey, but they were found to coexist in the second survey. It appears that the removal of the dam created more natural conditions in the river. As stated above, the pleurocerid was found mainly in shallow, slow-flowing water, while the neritid specimens were found both in quiet and swiftly-flowing water, somewhat different habitat conditions than that mentioned. Furujo and Tomiyama (2000) state that, where these two species coexist, some niche competition may exist with $S$. libertina rarely inhabiting rocky substrates. However, during the second river survey, in areas where both species were found together, $S$. libertina inhabited both larger rocks and gravel. This may be because of the relatively small numbers of $C$. retropictus.

The dimensions of the estuary and river specimens provided some information on the growth of individuals of this species. The smallest estuary specimens had a lower $\mathrm{L}$ minus $\mathrm{W}$ difference of 3 $\mathrm{mm}$, while the largest ones had a difference of $5 \mathrm{~mm}$ (Fig. 4a). The river specimens, smaller in size, exhibited the same trend, with the smallest specimens having a difference of $2 \mathrm{~mm}$ and the largest $4 \mathrm{~mm}$. (Fig. 4b)

Also, the $\mathrm{L} / \mathrm{W}$ ratios for both the estuary and river samples show a slight increase with larger sizes. In general, for the estuary specimens, the ratio is 1.2 for smaller specimens then rising to 1.3 as size increases. This trend is similar for the river specimens, from 1.2 to 1.3 , although the ratio for the two larger specimens drops to 1.2. This indicates that younger specimens are usually rounder but, as they grow older, they tend to become more ovate.

Shigemaya and Kato (2001) determined that the number of growth lines on shells of $C$. retropictus represented the ages of the specimens. An examination of the annual growth lines on both the estuary and river specimens, a total of 23 specimens, revealed that, in general, age correlated well with size (Fig. 5). The river population, a younger one, had an 
The Occurrence of Clithon retropictus (von Martens in Kobelt, 1879, Gastropoda: Neritidae) in Jeju Island,

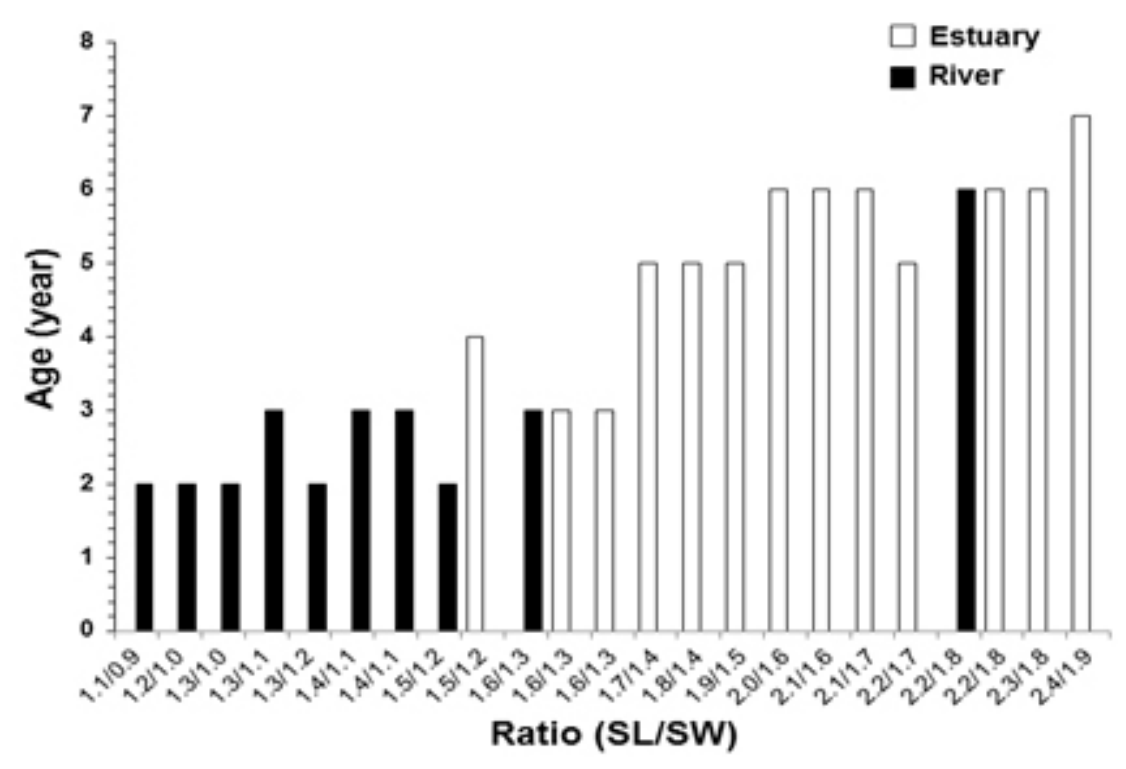

Fig. 5. Age and size correlation (estuary and river).

average estimated age of 2.8 years while the average estimated age of the estuary population, an older, well-established one, was 5.2 years. The above study also showed that younger populations were found in the lower reaches of rivers, with progressively older populations in the middle and upper reaches. In this study, a younger population was found in the lower reaches of the river near the sanitation plant, which corroborates the findings of Shigemaya and Kato. Although no sampling was done in the middle and upper reaches, older, larger-sized populations may exist there.

The absence of $C$. retropictus in the brackish water area in the river, resulting from the removal of the dam, may have been caused by the muddy sand substrate. This species seems to avoid sandy areas, and this also appears to be the main factor in the Gangjeong estuary, where the population is restricted to a rocky area along the western shoreline.

\section{CONCLUSION}

Since the publication of a catalogue of the mollusks of Jeju Island (Noseworthy et al., 2007), several other species have been added to the fauna. The occurrence of C. retropictus constitutes a new record and, for
Korea, a range extension to the island. Although there was some difference in morphology and color, specimens from both the river and estuary localities were quite similar, and compared well with mainland specimens and those in the literature. The relationship between length and width changes with age, the older individuals becoming more ovate; also the amount of shell erosion tends to increase with age. Further fieldwork may reveal the presence of this species in other localities.

Field studies on the island mollusks have been carried out by the authors for the past ten years, as well as by other researchers, and the fact that new species records keep occurring indicates the rich biodiversity of Jeju Island, both in the fauna in general, and the mollusks in particular. No doubt, other species will be added to the island fauna in the future.

There is certainly an urgent need for more baseline studies to enumerate not only the mollusks but also the fauna in general, which is a prerequisite for more in-depth research. The promotion of Jeju Island as a tourist destination is resulting in the continuous development of large areas of both the countryside and the coastline. It is important to ascertain, as completely as possible, the total diversity and scope of 
the fauna in the event that the natural aspect of large areas of the island is ruined by overdevelopment.

\section{ACKNOWLEDGEMENTS}

The authors would like to thank those who aided in the preparation of this study. The assistance of Koh Dong-Bum, Kang Hyun-Sil, Tom Eichhorst, John Wolff, Marlo Krisberg, Harry Lee, and the many knowledgeable members of the Conch-L Internet listserve is deeply appreciated. Thanks also go to the first author's family for their assistance and encouragement. This study was conducted as a part of the project titled "Assessment of the Impact of Climate Change on Marine Ecosystem in the south sea of Korea" (PM56600) funded by the Ministry of Land, Transport and Maritime Affairs, Korea.

\section{REFERENCES}

Ahn, K. K. 2002-2008. "Mike's Seashells". Available from WWW: <http://microseashell.com>

Davis, G. (1969) A Taxonomic Study of Some Species of Semisulcospira in Japan (Mesogastropoda: Pleuroceridae). Malacologia, 7(2-3): 211-294.

Eichhorst, T. "Clithon retropictus" pers. comm., unpublished manuscript, in press.

Environmental Bucket. 2001. Available from WWW: <http://www.01000.or.kr/xe/Wild_Photo/11889>

Furujo, Y. and Tomiyama, K. (2000) Distribution and Microhabitat of Coexisting Two Freshwater Snail Species, Semisulcospira libertina (Gould, Prosobranchia; Pleuroceridae) and Clithon retropictus (Martens, Prosobranchia: Neritidae). The Japanese Journal of Malacology. Venus, 59(3): 245-260 [in Japanese with English abstract].

Habe, T. (1975a) The Mollusks of Japan (Vol. I). Gakken Co. Ltd. Japan, Tokyo. 301 pp. [in Japanese].

Habe, T. (translated T. I. Elliott) (1975b) Shells of Japan (Hoikusha's Color Book Series No. 25) $\left(4^{\text {th }}\right.$ ed.). Hoikusha Publishing Company, Ltd. Japan, Osaka. 144 pp.

Haynes, A. (2005) An evaluation of members of the genera Clithon Montfort, 1810 and Neritina Lamarck, 1816 (Gastropoda: Neritidae). Molluscan Research, 25(2): 75-84. Available from WWW: <http://www.mapress.com.mr/>

Higo, S. and Goto, Y. (1993) A Systematic List of Molluscan Shells from the Japanese Is. and the Adjacent Area. Elle Corp. Japan, Osaka. $22+693$ $+13+149$ pp. (index). [in Japanese].
Hirase, S. (1951) A Handbook of Illustrated Shells in Natural Colors from the Japanese Islands and their Adjacent Territories (Isao Taki ed.). Bunkyokaku. Japan, Tokyo. 124 pp. [in Japanese]

Hirata, T., Ueda, H., Tsuchiya, Y., Sato, T., and Nishiwaki, S. (1999) Distribution of Clithon retropictus (Gastropoda; Neritidae) and environmental conditions in the rivers of Izu Peninsula. Bulletin of the Faculty of Education and Human Sciences, Yamanashi University, 1(1): 24 30. [in Japanese with English abstract]

Kira, T. (1964) Colored Illustrations of the Shells of Japan (Vol. I). Hoikusha Publishing Co., Ltd. Japan, Osaka. ix +240 pp. [in Japanese]

Kobayashi, S. and Iwasaki, K. (2002) Distribution and Spatio-temporal Variation in the Population Structure of the Fluvial Neritid Gastropod Clithon retropictus. Benthos Research, 57(2): 91 - 101.

Kumazawa, N. H, Kato, E, Takaba, T, and Yokota, T. (1988) Survival of Vibrio parahaemolyticus in two gastropod molluscs, Clithon retropictus and Nerita albicilla. Nihon Juigaku Zasshi, 50(4): 918-24. [in Japanese with English abstract]

Kwon, O.G., Min, D.-K., Lee, J.-R., Lee, J.-S., Je, J.-G. and Choe, B.-L. (2001) Korean Mollusks with Color Illustrations. Hangul Graphics. Korea, Busan. 332 pp. [in Korean]

Kwon, O.K., Park, G.-M. and Lee, J.S. (1993) Colored Shells of Korea. Academy Publishing Co. Korea, Seoul. 445 pp. [in Korean]

Martens, E. von. (1863-1879) Die Gattung Neritina. Systematisches Conchylien-Cabinet von Martini und Chemnitz 2 (10). 303 pp., pls. A, 1-23. [in German]

Matsuoka, K., Kimura, T., Kimura, S., Yamaguchi, K., and Takayasu, K. (1999) Molluscan Fauna of the lower reaches of the Toyogawa River. Science Report of the Toyohashi Museum of Natural History, 9: 15 - 24. [in Japanese with English abstract]

Min, D.-K., Lee, J.-S., Koh, D.-B. and Je, J.-G. (2004) Mollusks in Korea. Min Molluscan Research Institute. Korea, Seoul. 566 pp [in Korean]

"Neritopsine Gastropods" (2010) Available from WWW: $<$ http://neritopsine.lifedesks.org/taxa >

Noseworthy, R.G., Lim, N.R., and Choi, K.S. (2007) A Catalogue of the Mollusks of Jeju Island, South Korea. Korean Journal of Malacology, 23: 65-104.

Ohara, T. and Tomiyama, K. (2000) Niche Segregation of Coexisting Two Freshwater Snail Species, Semisulcospira libertina (Gould, Prosobranchia: Pleuroceridae) and Clithon retropictus (Martens, Prosobranchia: Neritidae). Japanese Journal of Malacology, 59(2): 135 - 147. [in Japanese with English abstract]

Okutani, T. (2000) Marine Mollusks in Japan. Tokai University Press. Japan, Tokyo. 1224 pp.

Pace, G. L. (1996) Andrews' Anatomical Studies and Their Taxonomic Significance for the Snail Family Neritidae. In: Elliott, N. B., Edwards, D. C., and 
The Occurrence of Clithon retropictus (von Martens in Kobelt, 1879, Gastropoda: Neritidae) in Jeju Island, Republic of Korea

Godfrey, P. J. (eds.) Proceedings of the Sixth Symposium on the Natural History of the Bahamas.

Bahamian Field Station, Ltd. Bahamas, San Salvador, pp. 126 - 133.

Shigemiya, Y. and Kato, M. (2001) Age distribution, growth, and lifetime copulation frequency of a freshwater snail, Clithon retropictus (Neritidae). Population Ecology, 43(2): 133 - 140.

Tan, S. T. and Clements, R. (2008) Taxonomy and Distribution of the Neritidae (Mollusca: Gastropoda) in Singapore. Zoological Studies, 47(4): 481-494. 